\title{
Hipotermia crónica y síndrome de mala adaptación en cocodri- lo de río (Crocodylus acutus): reporte de caso.
}

\section{Carta al Editor}

Armando Rubio-Delgado, Helios Hernández-Hurtado, Fabio G. Cupul-Magaña.

Departamento de Ciencias, Centro Universitario de la Costa, Universidad de Guadalajara, Puerto Vallarta, Jalisco, México.

Los reptiles pueden vivir un tiempo considerable y aún así alimentarse a temperaturas menores que las óptimas (menos de $15^{\circ} \mathrm{C}$ ). Sin embargo los efectos adversos incluyen disfunción de las enzimas digestivas, que ocasiona emesis (vómito) y gastroenteritis necrótica secundaria hasta un alto grado de putrefacción, otra causa sería la gota articular y visceral que resulta del metabolismo impedido y ausencia en la excresión proteíca como la solubilidad de uratos. Aunado a lo anterior, se tiene un aumento de susceptibilidad a infecciones, debido a que su inmunidad humoral y celular se encuentran restringidas. Con respecto al síndrome de mala adaptación, este término es utilizado para describir los problemas que pueden resultar por deficiencia para simular apropiadamente el hábitat natural. Estos problemas van desde deshidratación e inanición que se complican con infecciones secundarias por la pérdida de tejidos, incluyendo estomatitis y dermatitis ulcerativa y gastroenteritis necrótica (1).

Las enfermedades ambientales fueron detectadas en un cocodrilo de río juvenil (Crocodylus acutus) de aproximadamente $90 \mathrm{~cm}$ de longitud, $1.80 \mathrm{~kg}$ de peso, macho y con una edad tentativa de 3 años, proveniente de la región sureña del estado de Jalisco conocida como Chamela. Este ejemplar presentó laceraciones y mutilaciones en la extremidad derecha anterior.

Una vez puesto a disposición de las autoridades universitarias, el cocodrilo fue sometido a tratamiento a base de amikasina 0.5 $\mathrm{mg} / \mathrm{kg}$ acompañada de terapia de fluidos $(28 \mathrm{ml}$ de solución Hartmann) y dexametasona $0.18 \mathrm{mg}$, administrado por espacios de 72 hrs en cinco aplicaciones. Al cumplirse 25 días del tratamiento el ejemplar murió.

Solicitud de sobretiros: M. en C. Fabio G. Cupul-Magaña, Depto. de Ciencias, Centro Universitario de la Costa, U. de G., Av. U. de G. \# 203, Deleg. Ixtapa, C.P. 48280, Puerto Vallarta, Jalisco, México. Tel. y Fax: (328) 10520, 10521, 10522 E-mail: fcupul@pv.udg.mx

Recibido el 28/Enero/2000. Aceptado para publicación el 4/Febrero/2000. 
A Rubio-Delgado, H Hernández-Hurtado, FG Cupul-Magaña.

El examen postmorten evidenció necrosis en aparato digestivo y urinario, así como el inicio de una anquilosis articular (no observada en placa radiográfica). Por su parte al realizarse un cultivo de lesión, el antibiograma detectó a la bacteria Proteus mirabilis (microorganismo gramnegativo oportunista), la cual es encontrada en septicemias (2).

Para mantener marginados este tipo de padecimientos en organismos en cautiverio, es necesario semejar, en lo más posible, el hábitat natural de la especie en cuanto al control de humedad, temperatura, manejo y alimentación, bajo la estricta supervisión de un responsable técnico.

Palabras clave: Patología en reptiles, Crocodylus acutus.

\section{REFERENCIAS.}

1.- Birchard SJ, Sherding RG. 1996. Manual clínico de pequeñas especies. México: McGraw-Hill Interamericana; 1996. p. 1747.

2.- Piatkin, KD, Krivoshein YS. Microbiología. Moscú: Editorial Mir; 1981. p. 582.

\section{Revista Biomédica}

